\title{
Investigation of blast wave characteristics for layered thermobaric charges
}

\author{
W. A. Trzciński · K. Barcz
}

Received: 16 June 2010 / Revised: 1 November 2011 / Accepted: 9 February 2012 / Published online: 23 February 2012

(C) The Author(s) 2012. This article is published with open access at Springerlink.com

\begin{abstract}
The explosion of an annular charge composed of a hexogen core and a layer consisting of a mixture of ammonium nitrate and aluminum particles was studied. X-ray photography was used to trace the curvature of the shock wave in the external layer. The pressure blast characteristics and the light output of the explosion cloud were investigated using bunkers of different sizes and varying levels of the opening (the ratio of the hole surface to the total bunker surface). Overpressure peaks, the impulses of incident waves, and the impulses determined for the specified time duration were analyzed.
\end{abstract}

Keywords Thermobaric layered charges · Blast waves

\section{Introduction}

Fuel-enriched classic explosives, in which the blast characteristics are enhanced when the explosion products burn oxygen from the ambient air, are the most well-known thermobaric and enhanced blast explosives. The blast parameters can improved by adding metal microscopic powders such as magnesium or aluminum to the explosive. Composite explosive materials, which include an explosive casing and macroscopic non-explosive energetic inclusions, also can increase

Communicated by F. Zhang.

This paper was based on work presented at the 21 st International Symposium on Military Aspects of Blast and Shock, Jerusalem, Israel, 3-8 October 2010.

W. A. Trzciński $(\varangle) \cdot$ K. Barcz

Military University of Technology, Kaliskiego 2 Street,

00-908 Warsaw, Poland

e-mail: wtrzcinski@wat.edu.pl blast characteristics. This type of composition may exist in a cylindrical layer (shell) in an annular construction.

Recent patents [1,2] describe the use of a solid fuel-air explosive (SFAE). The SFAE may be formed from a metal composition that comprises a reactive metal, binder, and plasticizer, or a catalyst of choice. Another invention is the development of a class of charges using an annular design. In a typical annular construction, a cylindrical shell of a SFAE surrounds the high explosive charge. The SFAE charge may also include a mixture of reactive metals or metallized compositions with a high explosive.

Metallized explosives can be made in two ways. In the first composition, a solution of metal particles is coated by a polymer and then pressed. This composition can be used in an annular warhead next to a cylindrical charge of a polymerbonded explosive (PBX), basing on octogen (HMX), hexogen (RDX), or hexanitrohexaazaisowurtzitane (CL-20). The second type of composition is made by mixing, casting, and curing of a metal powder, or a mixture of metal powder and oxidizer, with a high explosive to create the PBX material. One of the compositions described previously [1] consists of about $60-96 \mathrm{wt} \%$ of reactive metal powder, $4-10 \mathrm{wt} \%$ of binder, and $0-36 \mathrm{wt} \%$ of oxidizer.

Another patent [3] describes solid explosive compositions, which upon exposure to a weak shock, disperse the comprised fragments instead of detonating and initiating their surface burning. However, this type of composition detonates when it is subjected to a strong shock. For example, the highly energetic fragmentized composition proposed in this patent consists of macroscopic particles, forming an insensitive explosive composition that includes a mixture of microscopic particles of a high explosive, a metal fuel, and a binder.

Thermobaric annular charges containing fragmentized compositions are also claimed in this patent [3]. After detonation, a cylindrical explosive charge generates a weak shock 
in a cylindrical layer consisting of the fragmentized composition. Macroparticles from the composition are ignited and dispersed by the shock wave. Dispersed particles burn in air that is heated by the shock front, and the additional energy enhances the blast wave.

An analysis of the data presented in these patents [1-3] shows that the oxidizer is a significant component of the explosive composition. Ammonium perchlorate, ammonium dinitroamide, ammonium nitrate, and barium nitrate are examples of these oxidizers. It is known that ammonium nitrate (AN) is a main component in mining explosives, but insufficient data exist for the application of this oxidizer in thermobaric compositions. Blast wave characteristics generated by charges consisting of mixtures of $\mathrm{AN}$ and $\mathrm{Al}$ powders were conducted previously [4]. Mixtures containing different contents of aluminum flakes or aluminum powder were tested. It was demonstrated that the blast wave peak measured for AN/Al charges was lower than that for phlegmatized RDX charges of the same mass. However, the overpressure impulses were comparable or even larger for the AN/Al compositions.

In this paper, the use of AN is investigated as a potential oxidizer in a composite mixture used in cylindrical layered charges. The explosion process with that type of charge is examined, and the blast wave characteristics and light output of the explosion cloud were determined.

\section{Experimental approach and results}

\subsection{Experimental setup}

A mixture of ammonium nitrate and aluminum is balanced by the oxygen amount needed for the complete combustion of aluminum and hydrogen, with a mass ratio of $\mathrm{AN}$ to $\mathrm{Al}$ of about $82 / 18$. The mass ratio is about $60 / 40$ if only aluminum is oxidized. In the thermobaric mixture, a minimum amount of oxidizer should be used, and oxygen should be utilized from ambient air during fuel combustion. In this investigation, mixtures containing 25, 50, and $75 \mathrm{wt} \%$ of AN were used as an oxidizer; thus, a mixture with an extremely negative oxygen balance ( $25 \mathrm{wt} \%$ ) and mixtures with oxidizer contents lower than those discussed above (50 and $75 \mathrm{wt} \%$ ) were tested.

Figure 1 shows a schematic of the investigated charges. The internal cylinder, with a diameter $\Phi_{1}=16$ or $25 \mathrm{~mm}$, was composed of pellets of RDX phlegmatized by wt $6 \mathrm{wt} \%$ wax (RDXph). The pellets had a density of $1.67-1.68 \mathrm{~g} / \mathrm{cm}^{3}$ and were stuck together. The total mass of the RDXph charges was either 44 or $109 \mathrm{~g}$. The detonation process was initiated by a standard electrical detonator. The AN/Al mixtures were external charges. Their density depended on the composition of the mixture, and were $1.25,1.14$, and

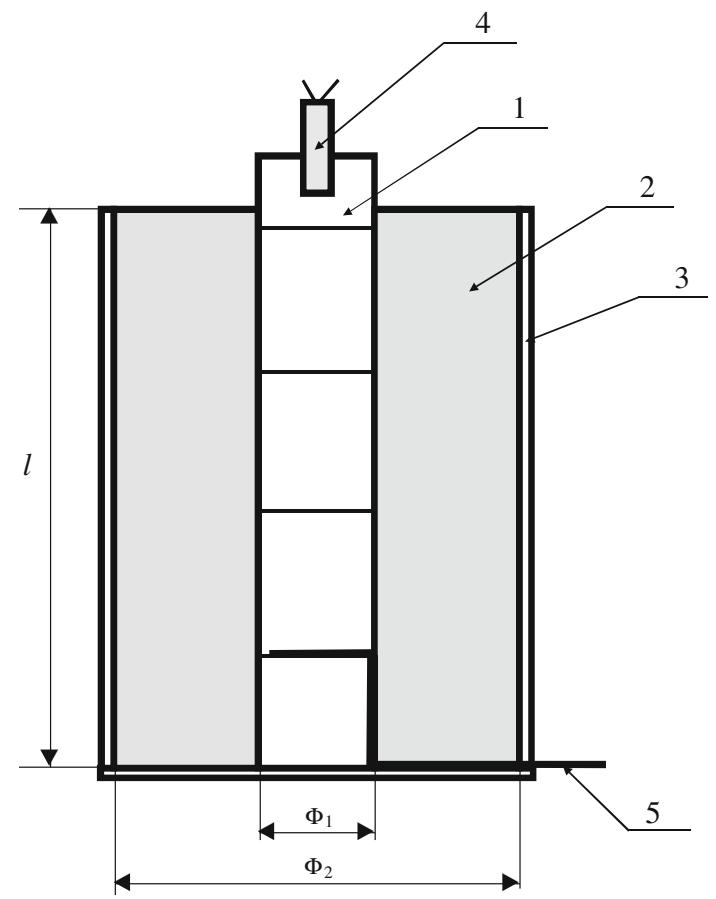

Fig. 1 A schematic of the investigated layered charge: $1 \mathrm{RDXph}, 2$ mixture of AN/Al, 3 paper tube with a thickness $3 \mathrm{~mm}, 4$ detonator, 5 sensor releasing the X-ray pulse, $\Phi_{1}$ diameter of the internal charge (16 or $25 \mathrm{~mm}), \Phi_{2}$ internal diameter of the paper tube, $l$ length of the AN/Al charge

$1.07 \mathrm{~g} / \mathrm{cm}^{3}$ for AN/Al mass ratios of 25/75, 50/50, and 75/25, respectively. The external diameter of all AN/Al charges was $\Phi_{2}=62 \mathrm{~mm}$ and their length was $l=120 \mathrm{~mm}$. Thus, the total mass of the mixtures with the AN/Al mass ratios of $25 / 75,50 / 50$, and $75 / 25$ were, in that order, about 360,380 , and $420 \mathrm{~g}$ for the small RDXph core and 320, 345 and $380 \mathrm{~g}$ for the larger core. Ammonium nitrate with particle sizes below $0.8 \mathrm{~mm}$ and aluminum powder $(99 \% \mathrm{Al})$ with particles below $75 \mu \mathrm{m}$ were used. A cylindrical charge was put into a paper tube having a thickness of $3 \mathrm{~mm}$.

The experiments were performed in both small and large bunkers. Figures 2 and 3 show schematics of the bunkers and the locations of charges and gauges. The large bunker has a volume of about $40 \mathrm{~m}^{3}$, and it has four small openings each with a surface of $0.05 \mathrm{~m}^{2}$ located at the top of the bunker and a frontage opening with a surface about $1.3 \mathrm{~m}^{2}$. The small bunker is a partially confined object with a volume about $25 \mathrm{~m}^{3}$. A fragment-proof casing (two layers of metal beams displaced relative to each other) is at the top of this bunker. There are also two front openings each with a surface about $1.75 \mathrm{~m}^{2}$. The charge was placed 1.5 and $1.3 \mathrm{~m}$ above the ground in the large and small bunker, respectively.

$\mathrm{X}$-ray impulse radiography was used to record the shock wave fronts in the explosive layered charge in the tests carried out in the small bunker. The X-ray source started when 


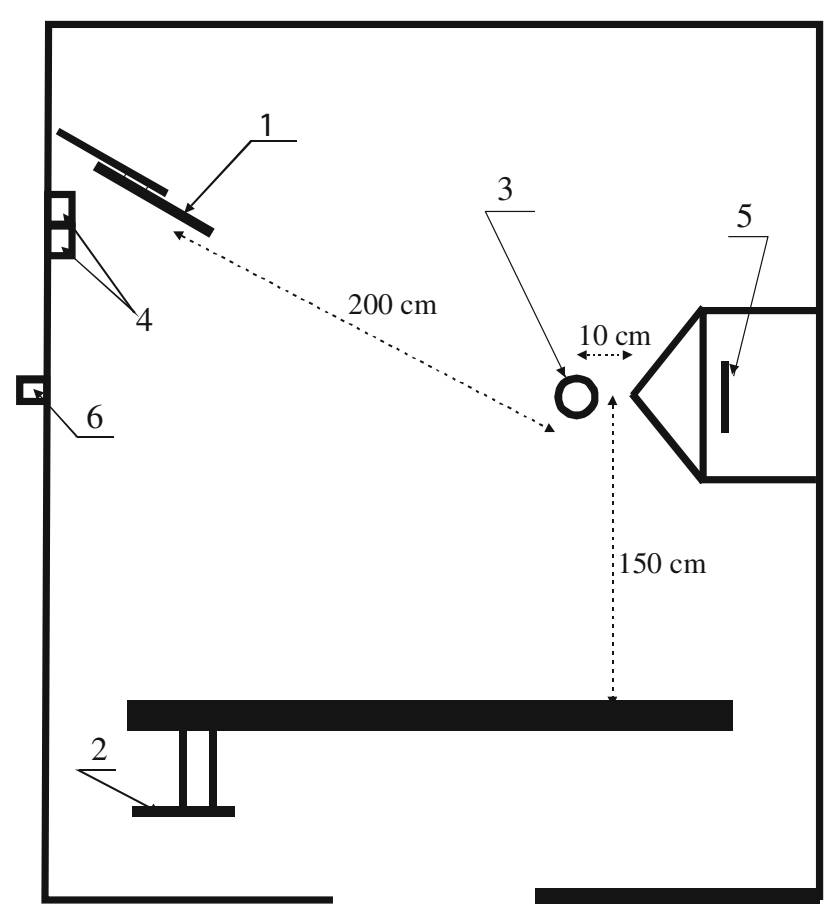

Fig. 2 A schematic of the small bunker with measurement equipment: 1 pressure gauge at a distance $2 \mathrm{~m}$ from the charge, 2 pressure gauge "behind the corner", 3 investigated explosive charge, 4 photodiodes, 5 film shield, $6 \mathrm{X}$-ray source

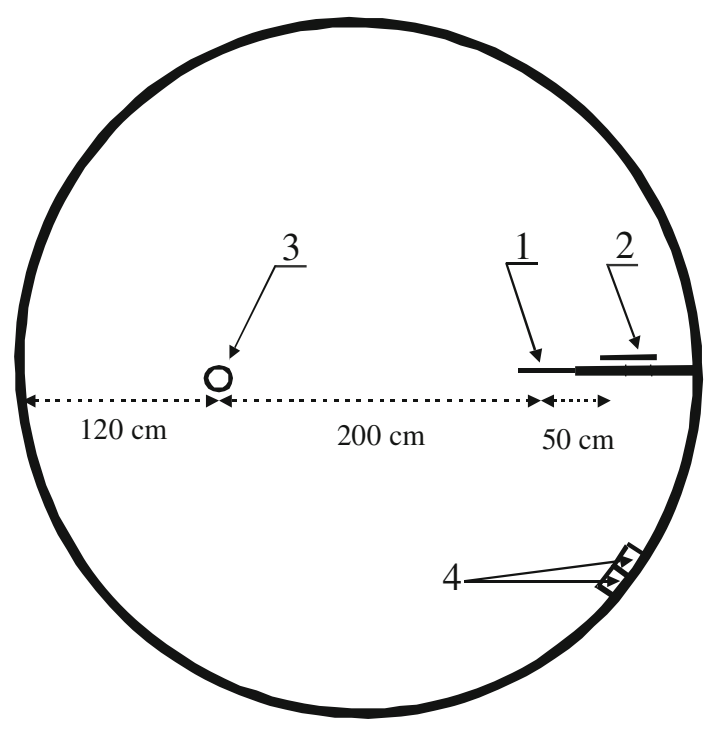

Fig. 3 A schematic of the large bunker with measurement equipment: 1,2 pressure gauges at distances $2 \mathrm{~m}$ and $2.5 \mathrm{~m}$ from the charge, respectively, 3 investigated explosive charge, 4 photodiodes

a detonation wave reached a short-circuit sensor (a shock collapsible sensor, see 5 in Fig. 1).

The blast pressure history was measured by piezoelectric gauges placed as shown in Figs. 2 and 3. Both gauges in the large bunker, and gauge 1 in the small bunker, recorded the overpressure of an incident shock wave, as it traversed the working surface of the devices. Gauge 2 from the small bunker (the gauge "behind the corner") measured the overpressure history of a wave as it reverberated from the bunker wall. Two photodiode systems were used to estimate the light output of the explosion charges. The first photodiode (OPT101) reacts only to a luminous intensity beyond some threshold. The signal from the second photodiode (BPDP35) was proportional to the light intensity.

\subsection{Exemplary results}

An exemplary X-ray photograph of the exploding charge is presented in Fig. 4, which shows the front of the detonation wave in the internal RDXph charge, and the shock fronts in the external AN/Al charge moving ahead of the contact boundary between the RDXph gaseous products and the compressed AN/Al mixture.

Exemplary blast wave measurements are shown in Figs. 5 and 6 for the large and small bunkers, respectively. Nearly the entire profile of the incident waves were recorded by both gauges in the large bunker, and by gauge 1 in the small bunker. After some period of time (1.5-2 ms), the profile is perturbed by the shock waves reflected by the bunker wall or the objects arranged inside the bunker (Fig. 2).

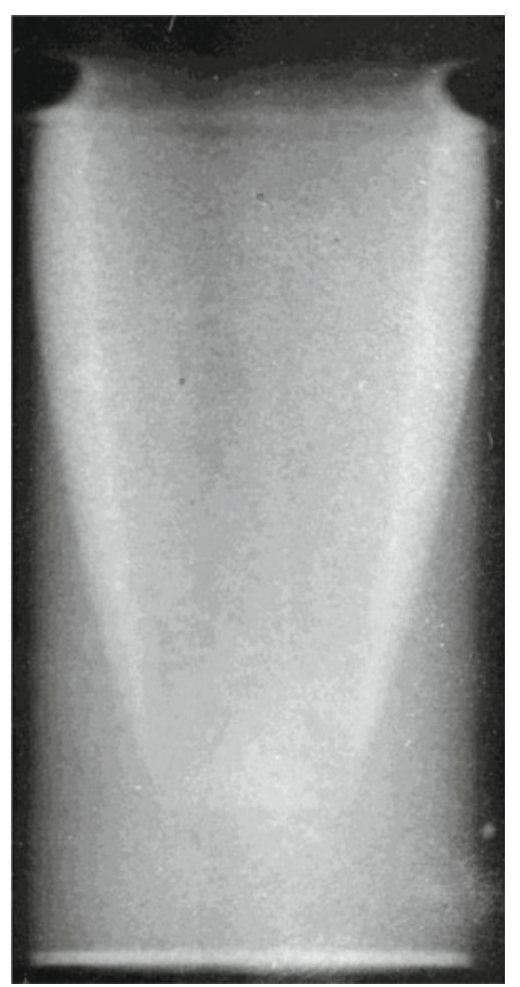

Fig. 4 X-ray photography of the exploding layered charge: RDXph $(\Phi=25 \mathrm{~mm})$ with a mixture $\mathrm{AN} / \mathrm{Al}=25 / 75$ 


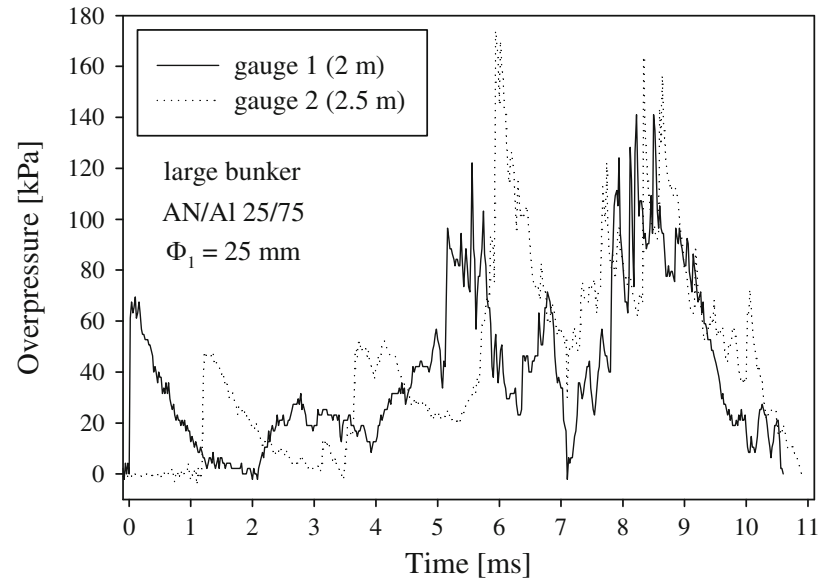

Fig. 5 Overpressure histories measured in the large bunker after the explosion of the layered charge: $\operatorname{RDXph}\left(\Phi_{1}=25 \mathrm{~mm}\right)$ with a mixture $\mathrm{AN} / \mathrm{Al}=25 / 75$

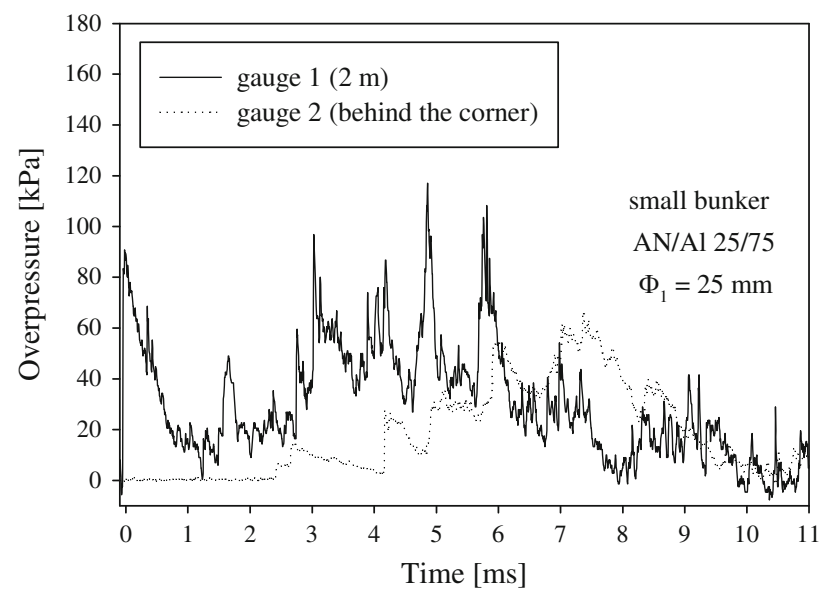

Fig. 6 Overpressure histories measured in the small bunker after the explosion of the layered charge: $\operatorname{RDXph}\left(\Phi_{1}=25 \mathrm{~mm}\right)$ with a mixture $\mathrm{AN} / \mathrm{Al}=25 / 75$

\section{Data analysis}

An investigation of wave front shapes was performed using mixtures containing $\mathrm{AN}$ and $\mathrm{Al}$ in the ratios 25/75 and 50/50. The shock front shapes in the blasting layered charges are presented in Fig. 7. For comparison, the shock fronts recorded for a powder of $\mathrm{Al}_{2} \mathrm{O}_{3}$ are also shown in the figure. The loose-packed density of aluminium oxide was $0.85 \mathrm{~g} / \mathrm{cm}^{3}$. There are very small differences between the wave profiles obtained for the different AN/Al compositions, 25/75 and 50/50, when the RDXph charge diameter remained same. This means that the parameters at the shock front are comparable for both AN/Al mixtures. The RDXph charge diameter has only a slight influence on the shock front curvature in the tested AN/Al mixtures.

The wave profiles presented in Fig. 7 for the two AN/Al mixtures are very similar to the shock front profile that was

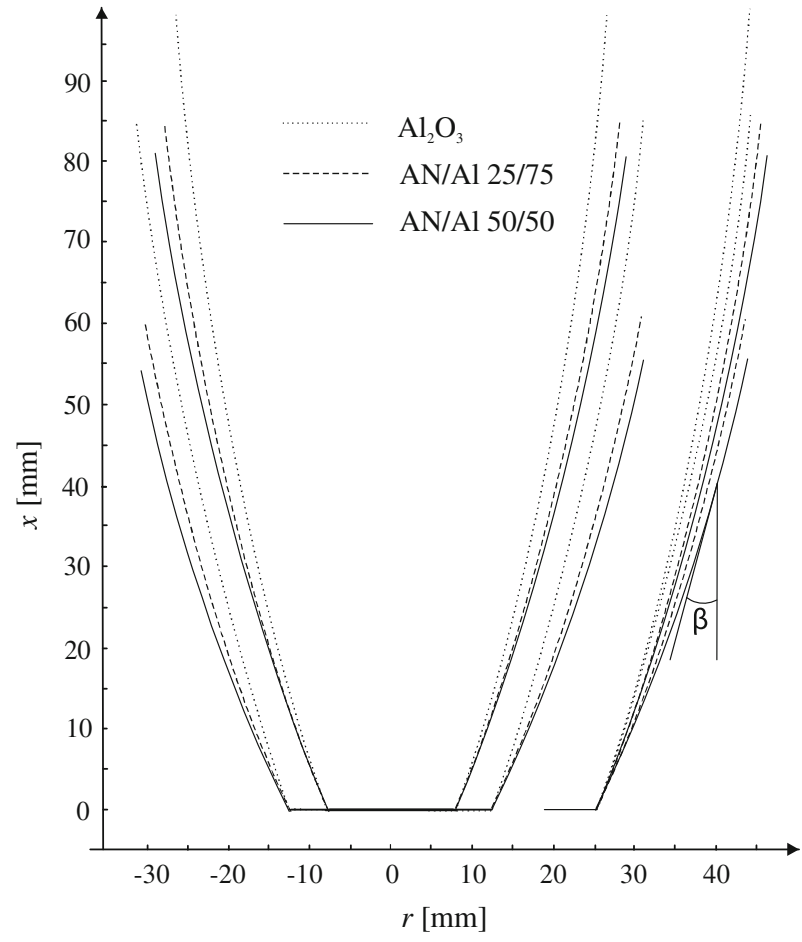

Fig. 7 Front wave profiles in the layered charges for two different diameters of the RDXph core (on the right of the figure the fronts are moved to allow comparison)

recorded for the inert $\mathrm{Al}_{2} \mathrm{O}_{3}$ powder. This implies that shock waves are generated in the mixtures instead of detonation waves. In order to investigate the change of the wave velocity in the outer layer, the wave propagation velocity in a direction perpendicular to its front was calculated from the obtained profiles. The wave velocity can be determined on the basis of the angle formed by the line tangent to the wave surface and the axis of the detonating RDXph core (the angle $\beta$ in Fig. 7). The lateral propagation velocity $D_{\mathrm{s}}$ is given by the following relation:

$D_{\mathrm{s}}=D \sin \beta$

in which $D$ is the detonation velocity of the RDXph core $(8,300 \mathrm{~m} / \mathrm{s}$ [5]). The dependence of calculated shock front velocities in the outer layers on distance to the RDXph core boundary are presented in Fig. 8 .

For all cases studied, the shock wave velocity in the outer layer decreases in a monotonic way with distance from the surface of the RDXph charge. If detonation occurred in a certain area of the outer layer, it would be a constant wave velocity [6]. So we can definitely say that a stationary detonation does not appear in the studied mixtures of AN/Al. However, the position of the curves in Fig. 8 suggests that the decomposition of ammonium nitrate behind the front wave and the strengthening this wave are possible. The smallest wave velocity was obtained for the inert powder $\mathrm{Al}_{2} \mathrm{O}_{3}$ which 


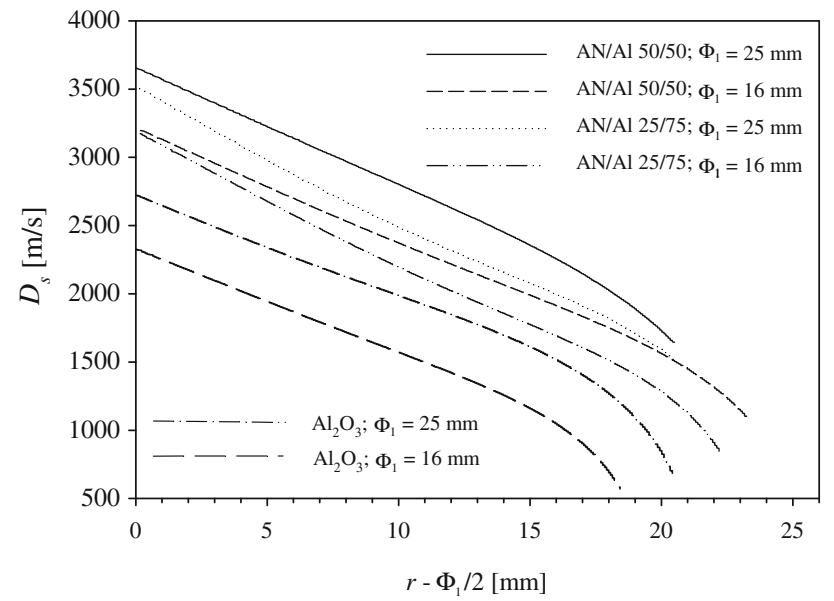

Fig. 8 Shock front velocity in the outer layers as a function of distance to the RDXph core boundary

has the lowest density from the materials used in tests. In this case the shock wave is absorbed in the greatest degree. But an inverse relation is observed for the AN/Al mixtures. The curves determined for a mixture of AN/Al 50/50 with a density of $1.14 \mathrm{~g} / \mathrm{cm}^{3}$ are above the curves obtained for a mixture of AN/Al 25/75 with a density of $1.25 \mathrm{~g} / \mathrm{cm}^{3}$. This evidence indicates that a strengthening of the wave in the initial phase of scattering is stronger in the first mixture. In this case, the greater amount of ammonium nitrate facilitates its gasification and the release of heat from the partial combustion of $\mathrm{Al}$ is more possible.

Figure 8 also shows that for a given packing of the outer layer the shock wave velocity determined for the core charge with a diameter of $\Phi_{1}=25 \mathrm{~mm}$ is greater than that obtained for the core of smaller diameter. Since the detonation velocity of RDXph for both charge diameters is similar [5], the cylindrical geometry of the system is responsible for different velocities of the shock wave for the same mixture in the outer layer.

A very important conclusion about the dispersal direction of the external charge can be drawn from the impulse radiography results for the AN/Al mixtures. The scatter from these mixtures is in the radial direction rather than in the axial direction. This has an important impact on the mixing of aluminum particles with air and their burning.

The overpressure history $\Delta p(t)$ can be used to determine the blast parameters. The blast wave is characterized by the overpressure peak wave and the specific impulse defined as

$I=\int_{0}^{\tau} \Delta p(t) \mathrm{d} t$

where $\tau$ is the duration of the positive overpressure wave.

The values of the overpressure peak and the specific impulse of an incident blast wave are presented in Figs. 9,

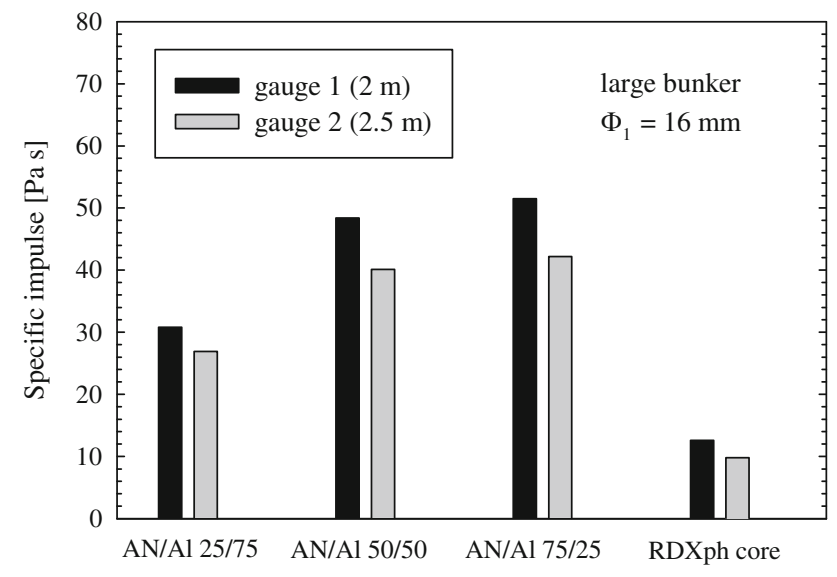

Fig. 9 Specific impulses of the incident blast waves for the charges having a RDXph core with a $16 \mathrm{~mm}$ diameter exploding in the large bunker

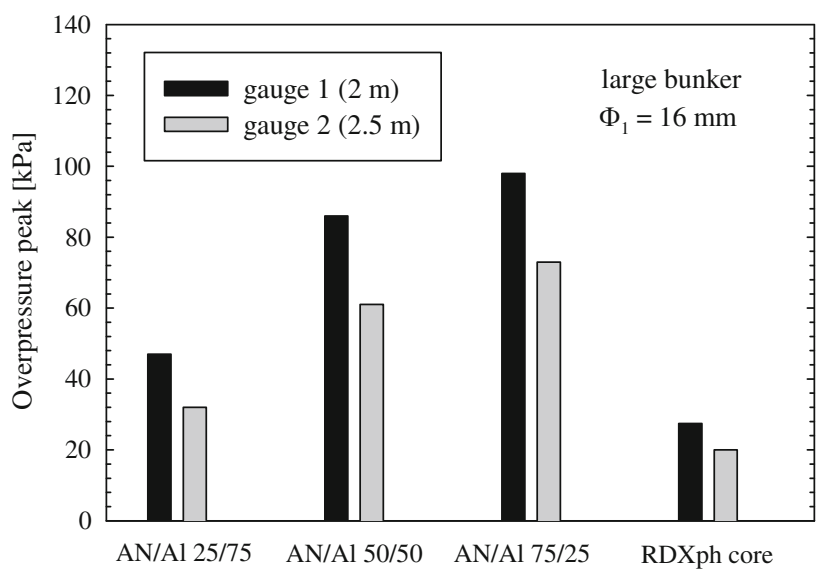

Fig. 10 Peak overpressures of the incident blast waves for the charges having a RDXph core with a $16 \mathrm{~mm}$ diameter exploding in the large bunker

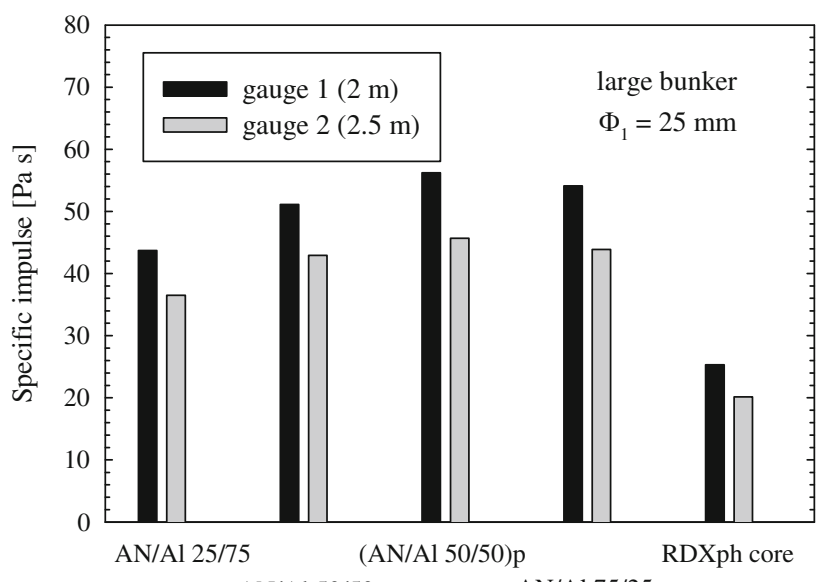

$\mathrm{AN} / \mathrm{Al}$ 50/50

AN/Al 75/25

Fig. 11 Specific impulses of the incident blast waves for the charges having a RDXph core with a $25 \mathrm{~mm}$ diameter exploding in the large bunker 


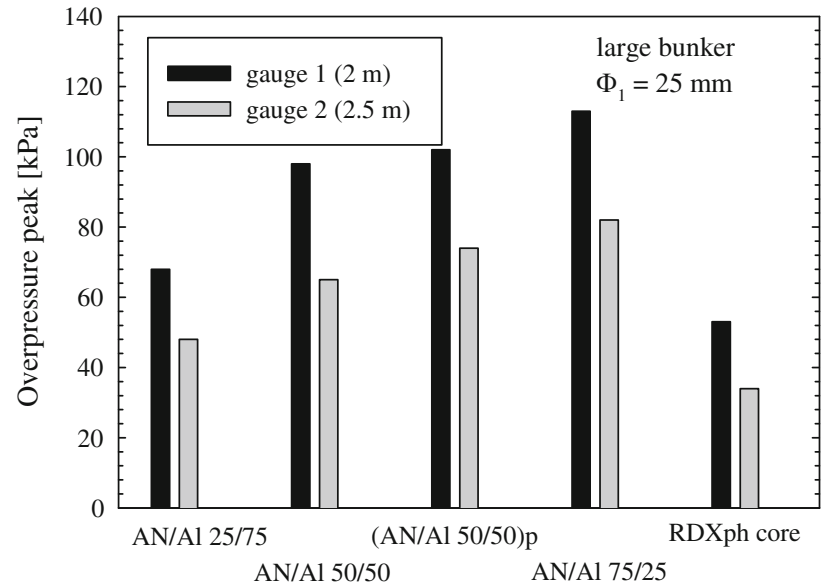

Fig. 12 Peak overpressures of the incident blast waves for the charges having a RDXph core with a $25 \mathrm{~mm}$ diameter exploding in the large bunker

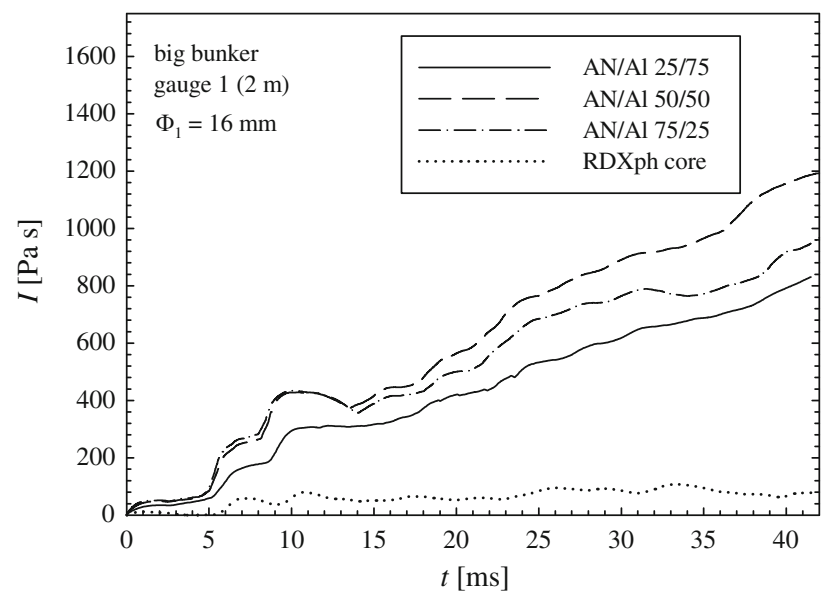

Fig. 13 Impulse histories at a distance $2 \mathrm{~m}$ for the $16 \mathrm{~mm}$ diameter charges in the large bunker

10, 11, 12 for the large bunker. Additionally, Figs. 12 and 13 include values for the pressed mixture of the RDXph and AN/Al 50/50, with the same mass of components as in the appropriate layered charge. The density of those charges was $1.88 \mathrm{~g} / \mathrm{cm}^{3}$. For comparison, the results obtained for the RDXph cores are also presented in Figs. 9, 10, 11, 12. The maximum difference between the values of the parameters set out in the various tests for the same charges did not exceed $10 \%$.

Both the peak overpressure and the impulse are enhanced as the proportion of AN increases in the mixtures. This relation suggests the decomposition of ammonium nitride and the possible reaction of its products with aluminum powder. The use of the $25 \mathrm{~mm}$ diameter RDXph charges having mass almost twice that of the $16 \mathrm{~mm}$ diameter charges increases the incident wave parameters only slightly (Figs. 9, 10, 11, 12). However, it should be noted that the largest increase in the peak and impulse values occurs for the composition
$\mathrm{AN} / \mathrm{Al}=25 / 75$. The results determined for the pressed charge of the RDXph and $\mathrm{AN} / \mathrm{Al}=50 / 50$ mixture are close to those obtained for the layered charge of the same composition. This means that the aluminum particles burn partially in the decomposition products of AN during the first stage of their dispersion.

The question is whether the decomposition of $\mathrm{AN}$ and oxidation of aluminum are possible in the rapidly expanding cloud of explosion products and the energy released may strengthen the primary blast wave at a distance of 2-2.5 m from the charge. From the data given in [7] it follows that some time is needed for decomposition of ammonium nitrate and burning of aluminum particles behind the detonation wave in a mixture of AN/Al. The burning time of Al particles under the condition of the detonation of AN/Al mixtures is roughly proportional to the particle diameter with exponent near 1.5. However, the analysis of the profiles of shock fronts in the AN/Al layers clearly shows that the process of decomposition of ammonium nitrate begins during the shock compression and start of burning of aluminum becomes possible. The experimental investigations of the explosive dispersion of a layer of aluminum powder or inert particles performed in [8] and [9] show that in the initial phase of scattering the blast wave in air is ahead of the boundary of particle cloud. However, this boundary is very close to the wave front, and at some distance from the charge the leading particles even pass the front. The dispersion of $270 \mathrm{~g}$ of aluminum powder enclosed in a glass sphere by using a $125 \mathrm{~g}$ spherical booster of $\mathrm{C} 4$ was investigated in [8]. Aluminum powders with average diameters of 5, 45, 100, and $200 \mu \mathrm{m}$ were used. It turned out that the boundary of particle clouds passed the blast wave front at a distance of approximately $0.7 \mathrm{~m}$ for the $200 \mathrm{~mm}$ particles and about $1 \mathrm{~m}$ for the smallest particles. Although the expansion of burning aluminum and gaseous products of AN decomposition is more complex than that of pure $\mathrm{Al}$ particles, it can be assumed that the first are also close to the blast wave front and the released energy can strengthen the primary blast wave.

The histories of the impulses calculated for a time period of about $40 \mathrm{~ms}$ were compared after the shock wave reached the gauges in the large bunker. This time period was chosen because the results at a later time are not repeatable. Moreover, from the measurements of the light output of the explosion, it follows that the light durations in the large bunker are of the order of $40 \mathrm{~ms}$ (Table 1). The exemplary impulse histories are compared in Figs. 13, 14, 15 and 16. The impulse values increase with time despite the bunker not being fully closed. This indicates that additional energy is released which maintains the average pressure inside the bunker, because the subsequent blast waves reflected from the bunker wall (Fig. 3) accelerate the turbulent mixing of the explosion products with air and increase the fuel (Al particles) combustion. In the case of RDXph cores the impulse initially increases 
Table 1 The light output of the explosion cloud of reactive products obtained from two photodiodes, BPDP35 and OPT101

\begin{tabular}{|c|c|c|c|}
\hline Mixture & $\mathrm{RDX}_{\mathrm{ph}}$ charge & Light output (BPDP35) [ms] & Light output (OPT101) [ms] \\
\hline \multicolumn{4}{|l|}{ Large bunker } \\
\hline \multirow[t]{2}{*}{ AN/Al 25/75 } & $\Phi 16$ & 80 & - \\
\hline & $\Phi 25$ & 58 & 52 \\
\hline \multirow[t]{2}{*}{ AN/A1 50/50 } & $\Phi 16$ & - & 43 \\
\hline & $\Phi 25$ & - & 41 \\
\hline \multirow[t]{2}{*}[\mathrm{RDX}_{\mathrm{fl}}/(\mathrm{AN}/\mathrm{Al}50/50)]{$_{\mathrm{p}}$} & $\Phi 50$ & 34 & 33 \\
\hline & & 36 & 34 \\
\hline \multirow[t]{2}{*}{ AN/Al 75/25 } & $\Phi 16$ & - & 26 \\
\hline & $\Phi 25$ & 33 & 31 \\
\hline \multirow[t]{2}{*}{ RDXph core } & $\Phi 16$ & 10 & - \\
\hline & $\Phi 25$ & 12 & - \\
\hline \multicolumn{4}{|l|}{ Small bunker } \\
\hline \multirow[t]{3}{*}{ AN/Al 25/75 } & $\Phi 16$ & 165 & 169 \\
\hline & $\Phi 25$ & 140 & 121 \\
\hline & & 142 & - \\
\hline \multirow[t]{2}{*}{$\mathrm{AN} / \mathrm{Al}$ 50/50 } & $\Phi 16$ & 139 & - \\
\hline & $\Phi 25$ & 103 & - \\
\hline
\end{tabular}

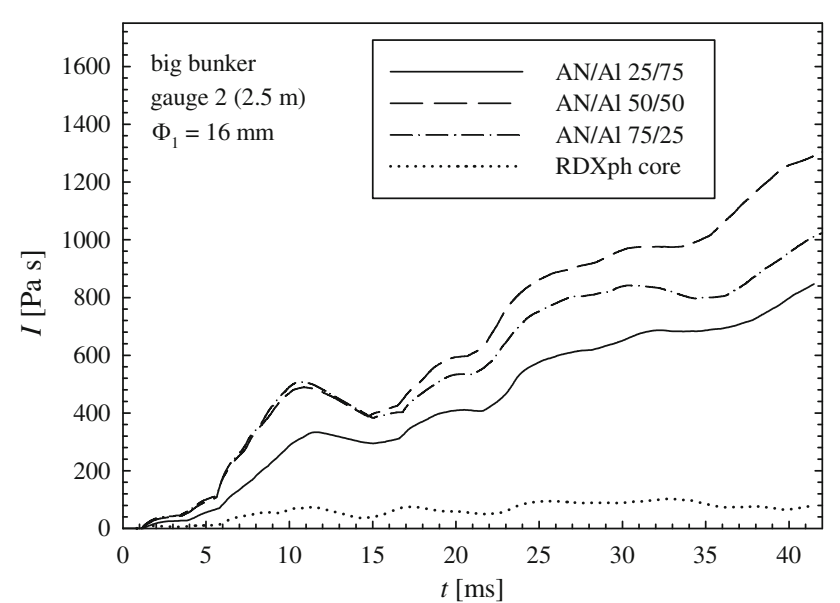

Fig. 14 Impulse histories at a distance $2.5 \mathrm{~m}$ for the $16 \mathrm{~mm}$ diameter charges in the large bunker

as a result of blast wave reflections from the surface of the sensors at an angle different from zero, but during the second stage of the pressure equilibration the impulse growth is very small due to the decreasing amount of gas in the bunker. If the bunker was closed completely the pressure impulse in this stage would grow with time in a linear way.

The results presented in Figs. 13, 14, 15, 16 show that for the smaller RDXph core, the final values of the impulses for the charge containing $\mathrm{AN} / \mathrm{Al}=25 / 75$ are the lowest; however, those obtained for the same composition in charges with a $25 \mathrm{~mm}$ diameter core are almost the highest. However, in the initial stage of expansion (approximately $10 \mathrm{~ms}$ ), the impulses for this charge are also the smallest (Figs. 15,

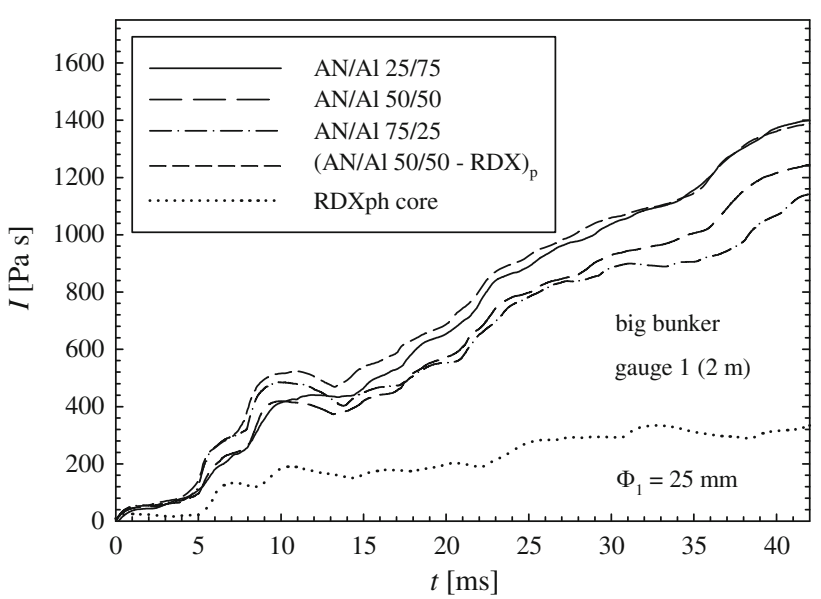

Fig. 15 Impulse histories at a distance $2 \mathrm{~m}$ for the $25 \mathrm{~mm}$ diameter charges in the large bunker

16). In our opinion, for every tested layered charge the combustion of aluminum particles is initiated in the early stage of expansion of the explosion cloud and the degree of conversion of aluminum during this period depends not only on its temperature but also on the availability of gaseous products of AN decomposition. Therefore, the impulse values are lowest for charges containing only $25 \% \mathrm{AN}$ in an outer layer (Figs. 13, 14, 15, 16). In the second stage, a mass of burnt aluminum mainly depends on the temperature value, because the amount of oxygen in the bunker significantly exceeds the amount of oxygen needed for complete combustion of aluminum used in each charge. In the case of larger charges the temperature in the bunker is greater, hence the 


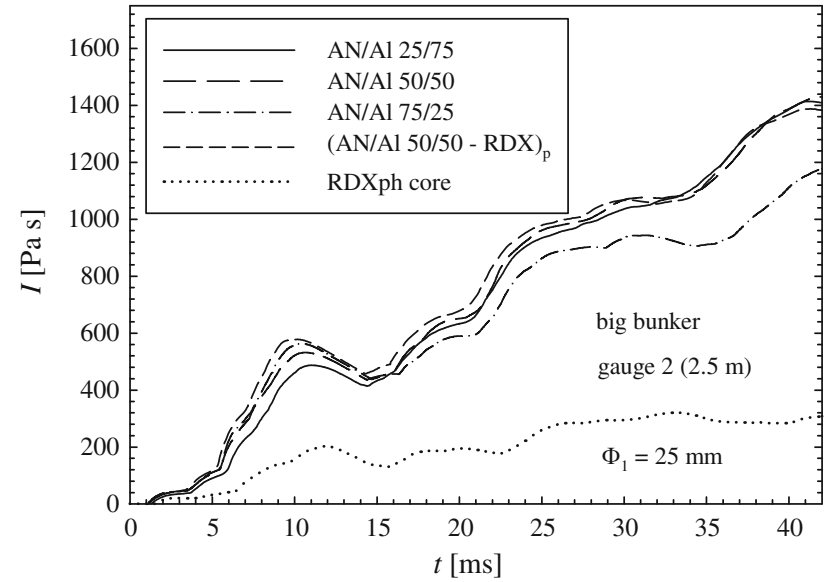

Fig. 16 Impulse histories at a distance $2.5 \mathrm{~m}$ for the $25 \mathrm{~mm}$ diameter charges in the large bunker

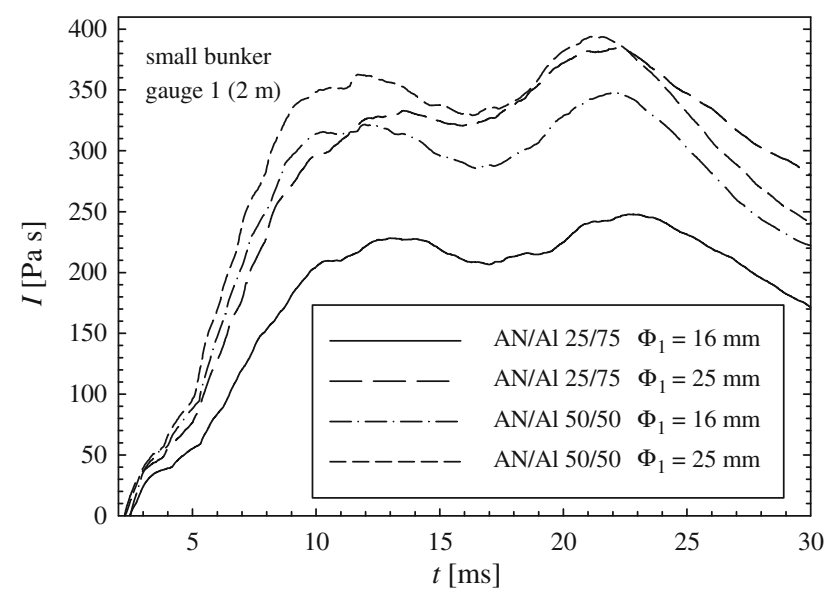

Fig. 17 Impulse histories at a $2 \mathrm{~m}$-distance in the small bunker

higher degree of burning aluminum powder and the higher pressure in the bunker. Also, the impulses estimated for the composition $\mathrm{AN} / \mathrm{Al}=75 / 25$ are the lowest in the second stage of the considered time period (Figs. 15, 16). In this case, the conditions in the bunker are appropriate for aluminum combustion, but the amount of $\mathrm{Al}$ powder is too small.

Exemplary impulse histories obtained for the small bunker are shown in Figs. 17 and 18. The impulse values initially increase with time, then later they rapidly fall since the bunker is semi-open. The relationships between the impulses determined for the layered charges with different contents of aluminum powder and the mass of the RDXph core are similar to those discussed earlier for the large bunker.

Table 1 shows the results of the light output of the explosion cloud obtained from two photodiodes. For the first photodiode, BPD35, the light output duration was determined to be the time period after which the voltage signal decreased to a value of $0.1 \mathrm{~V}$. The second photodiode made it possible to measure the duration of the light output directly, based on

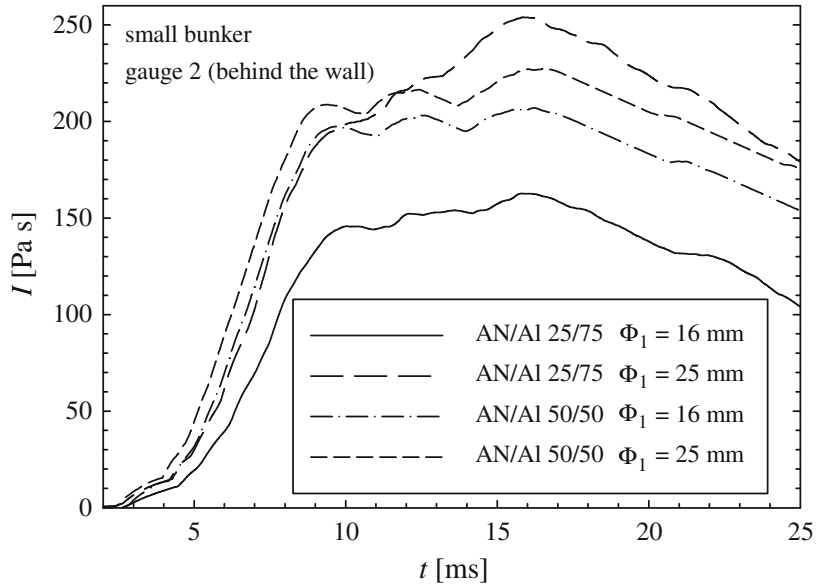

Fig. 18 Impulse histories behind the wall in the small bunker

the time period within which the voltage was sustained at its maximum value. It should be noted that the photodiode results were extremely disturbed making their interpretation very difficult.

The light outputs in the small bunker are definitely longer than those in the large bunker. This means that the aluminum combustion conditions in the small bunker are more favorable, in spite of the small bunker being semi-open. This suggests that the ratio of the charge mass and bunker volume is a very important factor influencing the combustion process. The reflected shock waves are stronger in the small bunker due to the shorter distance from a charge to the wall; this creates more effective heating of the reactive mixture inside the object. The influence of the ratio of the charge mass to a closed object volume on the afterburning of detonation products was analyzed carefully in previous work [10-12].

\section{Summary}

An analysis of the obtained results leads to the following conclusions:

1. The external layer composed of a mixture of fuel (Al) and oxidizer (AN) is compressed and dispersed by the shock wave and the expanding detonation products of the internal explosive charge. From an X-ray photo analysis, it appears that the detonation phenomenon does not occur in the external layer.

2. The measured blast wave characteristics and the light outputs of explosion clouds confirm the initiation of the ammonium nitrate decomposition process and aluminum particle combustion by the shock wave.

3. The size of the used phlegmatized hexogen core only slightly influences the aluminum combustion process after detonation of the layered charges in the bunkers. However, this influence can be observed in charges hav- 
ing the highest aluminum content $(75 \%)$ in the mixture with ammonium nitrate.

4. Oxygen from air is used for aluminum particle combustion during the late stage of particle dispersion.

5. The ratio of the charge mass to the bunker volume influences the aluminum oxidation process.

Open Access This article is distributed under the terms of the Creative Commons Attribution License which permits any use, distribution, and reproduction in any medium, provided the original author(s) and the source are credited.

\section{References}

1. Chan, M.L., Meyers, G.W.: Advanced thermobaric explosive compositions. Patent US 6,955,732 B1, 18 Oct 2005

2. Chan, M.L., Bui, D.T., Meyers, G., Turner, A.: Castable thermobaric explosive formulations. Patent US 6,969,434 B1, 29 Nov 2005

3. Guirguis, R.H.: Reactively induced fragmenting explosives. Patent US 6,846,372 B1, 25 Jan 2005

4. Paszula, J., Trzciński, W.A., Sprzątczak, K.: Detonation performance of aluminium-ammonium nitrate explosives. Cent. Eur. J. Energ. Mater. 5(1), 3-12 (2008)

5. Trzcinski, W.A., Cudziło, S., Szymańczyk, L.: Studies of detonation characteristics of aluminium enriched RDX compositions. Propellants Explos. Pyrotech. 32, 392-400 (2007)

6. Deffet, L., Fosse, C.: Axial initiation of multi-component explosives charges. In: Proceedings of Fourth Symposium (International) on Detonation, White Oak, USA, 12-15 October, pp. 156-166 (1965)
7. Komissarov, P., Ermolaev, B.S., Khasainov, B.A., Presles, H.-N.: Formal characteristics of aluminium burning rate law in non-ideal detonations of ammonium nitrate based mixtures. In: Proceedings of 34th International Pyrotechnics Seminar, Beaune, France, 8-11 October, pp. 707-717 (2007)

8. Sturtzer, M.O., Gregoire, Y., Eckenfels, D.: Experimental study of aluminium particles dispersed and ignited by high explosive. In: Proceedings of 21st International Symposium on Military Aspects of Blast and Shock, Jerusalem, Israel, 3-8 October, CD (2010)

9. Goroshin, S., Frost, D.L., Ripley, R., Zhang, F.: Measurement of particle density during explosive particle dispersal. In: Proceedings of 21st International Symposium on Military Aspects of Blast and Shock, Jerusalem, Israel, 3-8 October, CD (2010)

10. Trzciński, W.A., Paszula, J.: Confined explosions of high explosives. J. Tech. Phys. 41(4), 453-470 (2000)

11. Wolański, P., Gut, Z., Trzciński, W.A., Szymańczyk, L., Paszula, J.: Visualisation of turbulent combustion of TNT detonation products in a steel vessel. Shock Waves 10(2), 127-136 (2000)

12. Trzciński, W.A., Paszula, J., Wolański, P.: Thermodynamic analysis of afterburning of detonation products in confined explosions. J. Energ. Mater. 20(3), 195-222 (2002) 